\title{
Phenotypic detection of ESBL among E.coli and Klebiella pneumoniae by modified CLSI guidelines
}

\author{
Akshantha B Sangannavar ${ }^{1}$, Sumangala $B^{2, *}$, Sahana Shetty N.S ${ }^{3}$ \\ ${ }^{\mathbf{1} C}$ Consultant Microbiologist, ${ }^{2}$ Professor Head, ${ }^{3}$ Tutor, Dept. of Microbiology, Gokula Metropolis Clinical Laboratories, MS \\ Ramaiah Memorial Hospital, Bangaluru, Karnataka, Mandya Institute of Medical Sciences, Mandya, Karnataka, India
}

*Corresponding Author:

Email: sumangalabdr@gmail.com

\begin{abstract}
Introduction: Escherichia coli and Klebsiella pneumoniae cause a wide range of infections. Multidrug-resistance strains carrying resistance genes have become a growing problem worldwide. The ESBLs have emerged distinctly, especially in Escherichia coli and Klebsiella pneumoniae.

Material and Methods: 250 non repetitive isolates of E. coli and K. pneumoniae were isolated from different clinical samples (pus, urine, sputum, blood) for the study. Each isolate was tested for production of ESBL by CLSI recommended PCT and compared with Modified CLSI Method for ESBL detection.

Results: 133 E. coli and $117 \mathrm{~K}$. pneumoniae were isolated where $65.2 \%$ of ESBL were detected. With modified CLSI method, overall rate of ESBL positivity increased from $65.2 \%$ to $74.4 \%$.of E. coli and $74.3 \%$ of K. pneumoniae isolates were ESBL producers by modified CSLI Method.

Conclusion: All the clinical samples growing gram negative bacteria should be tested for ESBL, production. Considering the grave scenario of antibiotic resistance in our country, it is high time that all clinical laboratories start detecting these enzymes routinely and accurately.
\end{abstract}

Keywords: Escherichia coli, Klebsiella pneumoniae, ESBL, Modified CLSI guidelines.

\section{Introduction}

Antimicrobial resistance is a global health security emergency that is rising due to emergence of microorganisms that are no longer treatable because of their resistance to virtually all available antibiotic treatment options.

In 1990s, there was increasing appearance of extended spectrum $\beta$-Lactamase, presently metallo $\beta$ Lactamase prevalence is increasing.in current situation, multi-drug resistant bacteria have spread widely which is being seen through various mechanisms, of which resistance by production of enzymes are most common.

Emergence of antibiotic resistance in bacteria is a major concern in health care system. Bacteria have evolved different mechanisms of drug resistance. Resistance to $\beta$-Lactam antibiotics in gram negative bacilli is primarily mediated by $\beta$-Lactamases.

CDC estimates that in United States, more than two million people are sickened every year with antibiotic resistant infections, with at least 23,000 dying every year. ESBL (Extended Spectrum $\beta$-Lactamases) producing Enterobacteriaceae were first reported in 1983 from Germany \& since then a steady increase of these strains have been reported worldwide.

Bush, Jacoby \& Medeiros have classified $\beta$ Lactamases according to substrate profiles.

The prevalence of ESBLs in India has now reached epidemic proportions, ranging from $62 \%$ to $100 \%$ in Escherichia coli and Klebsiella spp. respectively as observed in the 10 Indian medical centre SENTRY study.
ESBL, AmpC $\beta$-Lactamases \& Carbapenemases are major $\beta$-Lactamases released by pathogenic gram negative bacilli.

$\beta$-Lactamases are the commonest cause of bacterial resistance to $\beta$-Lactam antimicrobial agents. Their spread destroyed the utility of benzylpenicillin against Staphylococci and has hugely undermined that of ampicillin against Enterobacteria and Haemophilus and Neisseria spp. New enzymes and new modes of production of old enzymes now threaten the value of extended-spectrum cephalosporins against enterobacteria. Further $\beta$-Lactamases, some of which will become important in the future, are described in most issues of Antimicrobial Agents and Chemotherapy and in other journals.

The current $\beta$-Lactamase classifications have reached a high level of complexity, making them less accessible to clinicians, infection control professionals, hospital management and politicians. From the clinical perspective, a revised comprehensible nomenclature scheme is therefore needed. The term extendedspectrum b-lactamases (ESBLs) has reached a broader audience over time, but is currently restricted to functional class $2 \mathrm{be} /$ molecular class $\mathrm{A}$, clavulanic acid inhibited enzymes with activity against extendedspectrum cephalosporins. The proposed new classification expands the definition of ESBL to other clinically important acquired $\beta$-Lactamases with activity against extended-spectrum cephalosporins and/or carbapenems. The classical class-A ESBLs have been designated ESBLA in this classification, whereas plasmid-mediated AmpC and OXA-ESBLs are classed 
as miscellaneous ESBLs (ESBLM). Lastly, the carbapenemases have been designated ESBLCARBA, ESBLs with hydrolytic activity against carbapenems. We believe that this simplified classification may encourage new groups of healthcare professionals to engage in the effort to prevent the spread of acquired $\beta$ Lactamases.

\section{Aim and Objectives}

1. Comparison of ESBL Positive isolates by CLSI Confirmatory Method and modified CLSI method.

2. To know the prevalence of $\beta$-Lactamase producing E.coli \& Klebsiella pneumoniae.

\section{Material and Methods}

All samples were routinely cultured on MacConkey and blood agar plates. These plates were routinely incubated at $37^{\circ} \mathrm{C}$ aerobically and after overnight incubation, they were checked for bacterial growth. The organisms were identified by their colony morphology, staining characters, pigment production, motility and other relevant biochemical tests as per standard laboratory methods of identification. Isolation and identification of organisms.

Suspected Gram negative organisms were identified by colony characteristics, motility, oxidase reaction, citrate utilization, indole and gas production and sugar fermentation reactions.Triple sugar iron agar was used for $\mathrm{H} 2 \mathrm{~S}$ production, sugar fermentation. Maintenance and preservation of culture strains Organisms grown in appropriate media for 18 hours were preserved in a nutrient agar slant at $2-8^{\circ} \mathrm{C}$ in a refrigerator. Samples (Sputum, pus, urine, blood, ear discharge) received for culture and sensitivity testing to microbiology laboratory of MIMS will be processed as following. The samples were plated onto blood agar and Macconkey agar. The Macconkey agar plate showing lactose fermenting (pink) colonies were confirmed to be E coli and Klebsiella pneumoniae by series of biochemical tests.

Clinical isolates of E. coli \& Klebsiella pneumonia identified as per above mentioned procedure was be selected for the study.
Quality Control (QC) organisms used for the study: E. coli ATCC 25922 Klebsiella pneumonia ATCC 700603 Modified Kirby-Bauer sensitivity testing method was used for this purpose. Muller Hinton agar media was used, which has PH 7.2-7.4. Media was transfer in to 90 mm diameter sterile Petri dishes to a depth of 4 (four) $\mathrm{mm}$. The surface was lightly and uniformly inoculated by cotton swab in three directions rotating the plate approximately $60^{\circ}$, to ensure even distribution. Prior to inoculation, the swab stick was dipped into bacterial suspension having visually equivalent turbidity to $0.5 \mathrm{McFarland}$ standards. The swab stick was then took out and squeezed on the wall of the test tube to discard extra suspension. Inoculated plates were incubated at 37 ${ }^{\circ} \mathrm{C}$ for 24 hours. On the next day, plates were read by taking measurement of zone of inhibition.

Testing for ESBL production:

a. Screening test: Following antibiotic disks will be placed on MHA after performing a lawn culture of the test organism, incubated at $35^{\circ} \mathrm{C}$ for 24 hours. The zone diameter is measured after 24 hours.

\begin{tabular}{|l|c|}
\hline \multicolumn{1}{|c|}{ Antibiotic } & $\begin{array}{c}\text { Zone size for possible } \\
\text { ESBL producing } \\
\text { strains }\end{array}$ \\
\hline Aztreonam $(30 \mu \mathrm{g})$ & $\leq 27 \mathrm{~mm}$ \\
\hline Cefotaxime $(30 \mu \mathrm{g})$ & $\leq 27 \mathrm{~mm}$ \\
\hline Cefpodoxime $(30 \mu \mathrm{g})$ & $\leq 22 \mathrm{~mm}$ \\
\hline Ceftazidime $(30 \mu \mathrm{g})$ & $\leq 22 \mathrm{~mm}$ \\
\hline Ceftriaxone $(30 \mu \mathrm{g})$ & $\leq 25 \mathrm{~mm}$ \\
\hline
\end{tabular}

Screen positive isolates are further tested for confirmation of ESBL production.

b. CLSI phenotypic confirmatory test-by disk diffusion method: After performing a lawn culture of the test organism, a $\geq 5 \mathrm{~mm}$ increase in zone diameter for cefotaxime $(30 \mu \mathrm{g}) \&$ ceftazidime $(30 \mu \mathrm{g})$ tested in combination with clavulanic acid(CA) versus its zone when tested alone confirms an ESBL producing organism. Study design: An observational clinical study.

Table 2: Distribution of E. coli and K. pneumoniae isolates in males and females

\begin{tabular}{|c|c|c|c|}
\hline \multirow{2}{*}{ Organism } & \multicolumn{2}{|c|}{ Gender } & \multirow{2}{*}{ Total } \\
\cline { 2 - 3 } & Female & Male & \\
\hline E. coli & $72(54.1 \%)$ & $61(45.9 \%)$ & $133(53.2 \%)$ \\
\hline K. pneumoniae & $31(26.5 \%)$ & $86(73.5 \%)$ & $117(46.8 \%)$ \\
\hline Total & $103(41.2 \%)$ & $147(58.8 \%)$ & $250(100 \%)$ \\
\hline
\end{tabular}

Above table shows distribution of isolates in males and females, where E. coli have been isolated 0with female preponderance. $117 \mathrm{~K}$. pneumoniae are isolated with male preponderance. 


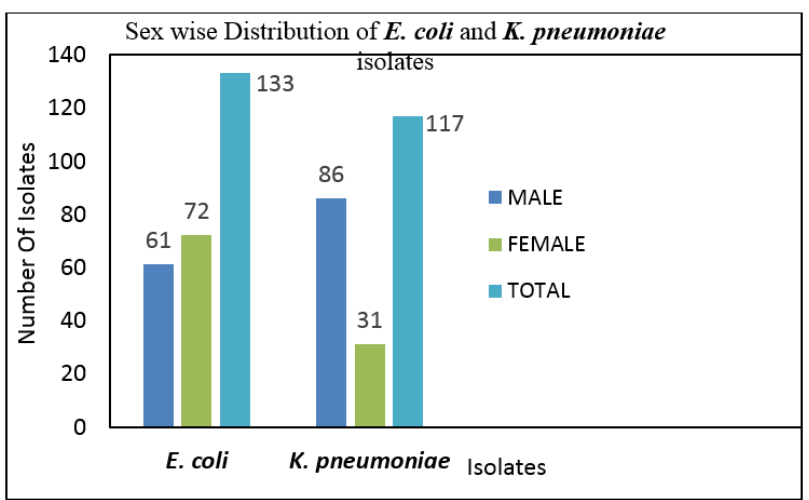

Fig. 1: Shows Sex wise Distribution of E. coli and K. pneumoniae isolates

Table 3: Age distribution of patients with E. coli and K. pneumoniaeisolates

\begin{tabular}{|l|c|c|c|}
\hline \multirow{2}{*}{ Age in years } & \multicolumn{2}{|c|}{ Organism } & \multirow{2}{*}{ Total } \\
\cline { 2 - 3 } & E. coli & K. pneumoniae & \\
\hline 1-30 days & 0 & $5(4.3 \%)$ & $5(2 \%)$ \\
\hline 1-12 months & $1(0.8 \%)$ & $1(0.9 \%)$ & $2(0.8 \%)$ \\
\hline 1-2 years & $2(1.5 \%)$ & $4(3.3 \%)$ & $6(2.4 \%)$ \\
\hline 3-5 years & $5(3.7 \%)$ & $2(1.7 \%)$ & $7(2.8 \%)$ \\
\hline 6-10 years & $3(2.3 \%)$ & $2(1.7 \%)$ & $5(2 \%)$ \\
\hline 11-15 years & $4(3 \%)$ & 0 & $4(1.6 \%)$ \\
\hline 16-20 years & $10(7.5 \%)$ & $5(4.3 \%)$ & $15(6 \%)$ \\
\hline$>20$ years & $108(81.2 \%)$ & $98(83.8 \%)$ & $206(82.4 \%)$ \\
\hline Total & $133(100 \%)$ & $117(100 \%)$ & $250(100 \%)$ \\
\hline
\end{tabular}

Above table shows age distribution and isolate distribution in patients studied, where majority of samples 206(82.4\%) were received from patients aged more than 20yrs. 17 (12.8\%) samples were in age between 11-25 years from urine of females with UTI. Only K. pneumoniae was isolated from neonates (blood culture and sensitivity).

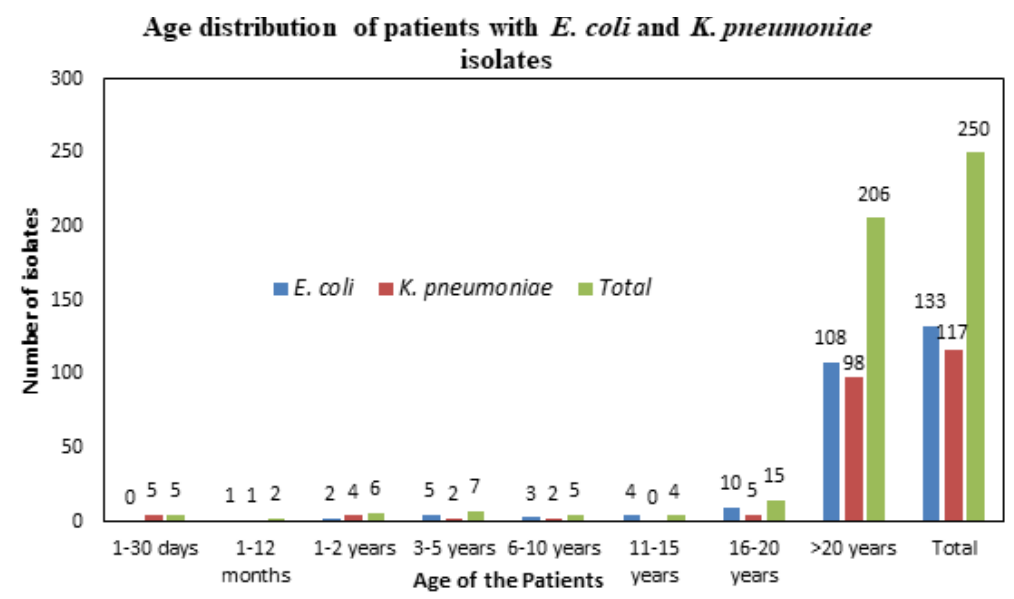

Fig. 2: Age distribution of patients with $\mathrm{E}$. coli and $\mathrm{K}$. pneumonia isolates

Table 4: Sample wise distribution of isolates

\begin{tabular}{|l|c|c|c|c|c|}
\hline \multicolumn{1}{|c|}{ Organism } & PUS & Sputum & Urine & Blood & Total \\
\hline E. coli & $50(37.6 \%)$ & $13(9.8 \%)$ & $70(52.6 \%)$ & 0 & $133(100 \%)$ \\
\hline K. pneumoniae & $46(39.3 \%)$ & $50(42.7 \%)$ & $15(12.8 \%)$ & $6(5.2 \%)$ & $117(100 \%)$ \\
\hline Total & $96(38.4 \%)$ & $63(25.2 \%)$ & $85(34 \%)$ & $6(2.4 \%)$ & $250(100 \%)$ \\
\hline
\end{tabular}

Out of 250 samples studied, majority of samples 96(38.4\%) were from pus, 85(34\%) were from urine and 63(25.2\%) from sputum. E.coli was isolated 133 out of 250 samples, 70(52.6\%) from urine samples majority were 
young females suffering from UTI. K. pneumoniae was isolated from 117 out of 250 samples, 50(42.7\%) from sputum samples, 46(39.3\%) from pus samples and 15(12.8\%) from urine samples. From blood samples only K. pneumoniae was isolated in 6 cases.

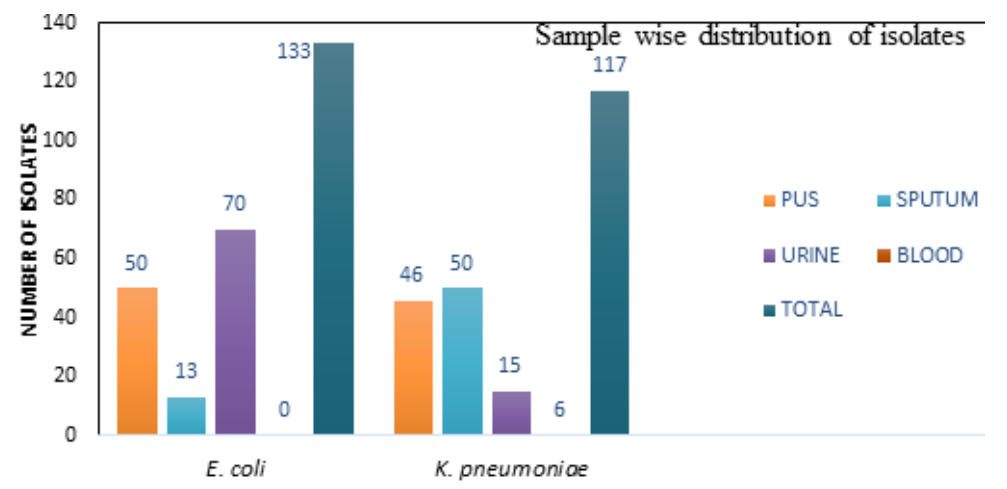

Fig. 3: Sample wise distribution of isolates

Table 5: Distribution of isolates showing ESBL positive by Screening and confirmatoty test

\begin{tabular}{|l|c|c|c|c|}
\hline \multicolumn{1}{|c|}{ Organism } & \multicolumn{2}{c|}{ ESBL by Screening } & \multicolumn{2}{c|}{ ESBL Confirmed } \\
\hline & Negative & Positive & Negative & Positive \\
\hline E. coli $(\mathrm{n}=133)$ & $25(18.8 \%)$ & $108(81.2 \%)$ & $45(33.8 \%)$ & $88(66.2 \%)$ \\
\hline K. pneumoniae $(\mathrm{n}=117)$ & $29(24.8 \%)$ & $88(75.2 \%)$ & $42(35.9 \%)$ & $75(64.1 \%)$ \\
\hline Total(n=250) & $54(21.6 \%)$ & $196(78.4 \%)$ & $87(34.8 \%)$ & $163(65.2 \%)$ \\
\hline
\end{tabular}

Above table shows detection of ESBL. Out of 133 E. coliisolated, 108(81.2\%) screened positive and 88(66.2\%) were confirmed ESBL by CLSI recommended method and Out of $117 \mathrm{~K}$. pneumonia isolated, 88(75.2\%) screened positive and $75(64.1 \%)$ confirmed positive for ESBL.

Table 6: Comparison of ESBL Positive isolates by CLSI Confirmatory Method and modified CLSI method

\begin{tabular}{|l|c|c|c|}
\hline \multicolumn{1}{|c|}{ Organism } & $\begin{array}{c}\text { ESBL Positive by } \\
\text { CLSI Screening } \\
\text { method }\end{array}$ & $\begin{array}{c}\text { ESBL Positive by } \\
\text { CLSI Confirmatory } \\
\text { Method }\end{array}$ & $\begin{array}{c}\text { ESBL Positive } \\
\text { by modified } \\
\text { CLSI Method }\end{array}$ \\
\hline E. coli $(\mathrm{n}=133)$ & $108(81.2 \%)$ & $88(66.2 \%)$ & $99(74.4 \%)$ \\
\hline K. pneumoniae $(\mathrm{n}=117)$ & $88(75.2 \%)$ & $75(64.1 \%)$ & $87(74.3 \%)$ \\
\hline Total $(\mathrm{n}=250)$ & $196(78.4 \%)$ & $163(65.2 \%)$ & $186(74.4 \%)$ \\
\hline
\end{tabular}

Comparison of ESBL Positive Isolates by CLSI Confirmatory Method and Modified CLSI Method

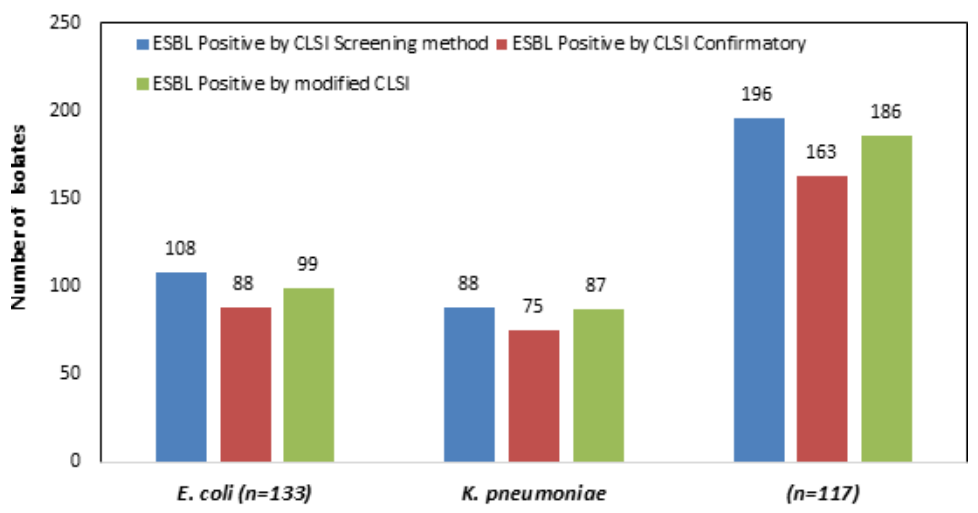

Fig. 4: Comparison of ESBL Positive isolates by CLSI Confirmatory Method and modified CLSI method with modified CLSI method, overall rate of ESBL positivity increased from 65.2\% to 74.4\% . 74.4\% of E. coli and $74.3 \%$ of $\mathrm{K}$. pneumoniae isolates were ESBL producers by modified CSLI Method. 


\section{Discussion}

Table 2 shows gender distribution of isolates where female preponderance of $\mathrm{E}$. coli can be attributed to UTI caused by the organism. In the present study, a total of 250 strains are studied, of which 133 are E. coli and 117 are $\mathrm{K}$ pneumoniae. Most of the isolates are from sample collected from patients aged over 20 years as shown in table 2, which can be attributed to their environmental exposure and outdoor activity of the manual ESBL confirmation methods, disk augmentation displayed the overall highest positivity rate, whereas Etest detected ESBL production in only $2 / 26$ isolates and yielded a high number of nondeterminable results.

\section{Conclusion}

ESBLs producing Gram-negative bacteria are an increasing public health problem worldwide because of their resistance to $\beta$ - lactam antibiotics. ESBL, AmpC and carbapenemase genes are typically carried on transferable plasmids or are part of the bacterial chromosome.

\section{References}

1. Bush K, Jacoby GA, Medeiros AA. A functional classificationscheme for $\beta$-lactamases and its correlation with molecular structure. Antimicrob Agents Chemother 1995;39:1211-33.

2. Mathai D, Manoharan A, Vasanthan G. Epidemiologyand Implications of ESBL. Crit Care Update2009;14:152-62.

3. Thomson KS. Extended-Spectrum- $\beta$-Lactamase, AmpC, and Carbapenemase Issues. J Clin Microbiol 2010;48(4):1019-25.

4. Nathisuwan S, Burgess DS, Lewis JS. ESBLs: Epidemiology, Detection and Treatment Pharmacotherapy 2001;21(8):920-28.
5. Jacoby GA, Han P. Detection of extended-spectrum betalactamases in clinical isolates of Klebsiellapneumoniae and Escherichia coli. J Clin Microbiol 1996;34(4):90811.

6. Xu L, Ensor V, Gossain S, Nye K, Hawkey P. Rapid detection of CTX-M genes by multiplex PCR assay. $J$ Med Microbiol 2005;54:1183-87.

7. Gupta V, Kumarasamy K, Gulati N, Garg R, Krishnan P, Chander J. AmpC $\beta$-lactamases in nosocomial isolates of Klebsiellapneumoniae from India. Ind J Med Res 2012;136:237-41.

8. Swarna SR, Srimathi NN, Radha Madhavan \& Gomathi S. Correspondence Performance of extended spectrum beta lactamases (ESBL) screening agar in various clinical specimens. Ind J Med Res 2015;141(4):481-82.

9. Rao SP, Rama PS, Gurushanthappa V, Manipura R, Srinivasan K. Extended-Spectrum Beta-Lactamases Producing Escherichia coli and Klebsiellapneumoniae: A Multi-Centric Study Across Karnataka. J Laboratory Physicians 2014;6(1):7-13.

10. Shashwati N, Kiran T, Dhanvijay AG. Study of extended spectrum $\beta$-lactamase producing Enterobacteriaceae and antibiotic coresistance in a tertiary care teaching hospital. Journal of Natural Science, Biology Med 2014;5(1):30-5.

11. Yong D, Toleman MA, Giske C, et al. Characterization of a New Metallo- $\beta$-Lactamase Gene, blanDM- 1 , and a Novel Erythromycin Esterase Gene Carried on a Unique Genetic Structure in Klebsiellapneumoniae Sequence Type 14 from India. Antimicrob Agents Chemother 2009;53(12):5046-54.

12. Babypadmini S, Appalaraju B. Extended spectrum lactamases in urinary isolates of Escherichia coli and Klebsiellapneumoniae-prevalence and susceptibility pattern in a tertiary care hospital. Ind J Med Microbiol 2004;22(3):172-4.

13. Rodriguez GJA, Jones RN. Antimicrobial resistance in gram-negative isolates from European intensive care units: data from the Meropenem Yearly Susceptibility Test Information Collection (MYSTIC) programme. $J$ Chemother 2002;14:25-32. 